\title{
EL CONCEPTO DE LA ESCUELA \\ DE SALAMANCA: \\ SUS ORIGENES Y SU DESARROLLO
}

\author{
MARJORIE GRICE-HUTCHINSON
}

Después de una larga serie de esfuerzos acumulativos, los historiadores del Pensamiento Económico se han puesto sustancialmente de acuerdo sobre cuáles han sido los principales aportes de la escolástica española a la ciencia económica. Radican éstos en el desarrollo de la teoría del valor y del precio, la integración de la teoría monetaria en la teoría general de los precios, la teoría cuantitativa del dinero, una interesante teoría de los cambios, la doctrina general del interés y el análisis del sistema tributario. Se trata de ideas que surgieron en la consideración de las grandes cuestiones fundamentales del justo precio, de la usura y de los tributos.

Donde sí hay una cierta diversidad de opinión es sobre la agrupación de los autores escolásticos españoles. ¿Qué nombre podemos emplear para designarlos? ¿Es lícito, por ejemplo, hablar de una «Escuela de Salamanca»? $\mathrm{Y}$ si es lícito, ¿sería posible concretar mejor nuestro concepto, o tendremos que seguir aludiendo siempre a una Escuela de Salamanca entre comillas, o tímidamente precedida por la palabra «llamada»?

El nombre de la «Escuela de Salamanca» aplicado a un grupo de iusnaturalistas y moralistas españoles del siglo xvI goza de una historia respetable. En 1954, en el séptimo centenario de la fundación de la Universidad de Salamanca, dijo Luciano Pereña que los artífices del pensamiento político español son Francisco de Vitoria, Diego de Covarrubias, Martín de Azpilcueta y Domingo de Soto. Contemporáneos, ocuparon simultáneamente las principales cátedras de teología y de derecho. A lo largo de su estudio, Pereña habla de la escuela salmantina, la escuela española de derecho internacional, los doctores de Salamanca, los maestros de Salamanca, o sencillamente «la escuela»'.

Al retroceder unos años más, encontramos las mismas opiniones expresadas por el P. Venancio Carro, el P. Beltrán de Heredia, y en el extranjero, por el norteamericano Scott Brown Scott, el francés Ernest Nys, y el sabio

\footnotetext{
' Pereña (1954), pp. 17-42.
} 
alemán Martin Grabmann, quien afirmó en 1917 que la regeneración de la escolástica debida a Vitoria no se limita a los teólogos dominicos. Los miembros de otras Ordenes religiosas han aprendido en esta escuela. Los teólogos de la Compañía de Jesús recibieron, en parte directa, en parte indirectamente, este estímulo y esta influencia de la Escuela de Salamanca, y la aprovecharon y desarrollaron en sus nuevos centros docentes y especialmente en Coimbra ${ }^{2}$.

El reconocimiento de la contribución española no sólo en el orden teológico, político y jurídico, sino también en el económico, no es totalmente nuevo. Aparece claramente en el libro de Wilhelm Endemann, publicado en 1874 y todavía aprovechable ${ }^{3}$. Y en 1927 y 1928 André Sayous recogía las opiniones que sobre los cambios monetarios ya adelantaron varios escritores franceses, italianos y españoles del siglo xvi. Sayous cree que los más sugestivos son los españoles. ¿Por qué?, se pregunta:

«Le motif est, croyons-nous, que la foire de Medina del Campo et les nouvelles relations avec l'Amérique ont placé les espagnols en face de situations extremement importantes et remarquables, don ils ont tirés d'utiles renseignements.»

Sayous se ocupa particularmente de Tomás de Mercado, citando por primera vez algunos de los textos que después llegaron a ser muy conocidos. Los demás autores españoles que menciona son de una importancia desigual: Juan Díez Freyle, Cristóbal de Villalón, Luis Saravía de la Calle, Luis de Alcalá y Francisco García. Sayous no habla de una «escuela de Salamanca» y no examina ninguno de los grandes tratados escritos en latín en que Mercado basa su doctrina ${ }^{4}$.

En el otoño de 1941 y primavera de 1942 el profesor Ullastres publica dos excelentes artículos en los que analiza la teoría monetaria de Martín de Azpilcueta ${ }^{5}$. Por desgracia, Ullastres creía que el Comentario en que el doctor navarro desarrolla su doctrina fuera publicado en 1570 en lugar de 1556.

2 «Nicht bloss auf Dominikaner theologen hat sich diese von Vitoria ausgehende Regeneration der Scholastik erstreckt, auch Angehörige anderer Orden haben in dieser Schule gelernt. Der Augustiner, Luis von Leon, ist ein Schüler von Melchor Cano. Auch Theolo. gen der in dic Wissenschaftlichen Bewegungen machting eingegreifen Gesellschaft Jesu haben in Spanien teils unmittelbar, teils mittelbar diese Anregungen und Einwirkungen der Schule von Salamanca in sich aufgenomen und in ihren neugegrundeten Studienzentren, besonders zu Coimbra, verwerten und weitergebildet." Martin GrabmanN, "Die Disputationes metaphysicae des Franz Suarez in ihrer methodischen Eigenart und Fortentwicklung», en P. Franz SuAre.z, S. J., Gedenkblatter zu scinem dreibundertiäbrigen, Todestag (25 sept. 1917), Innsbruck, 1917, p. 29, citado por Weber (1959), p. 11.

${ }^{3}$ Endemann (1874).

Sayous (1927), pp. 1417 et seq.; Sayous (1928).

${ }^{5}$ Ullastres (1941-1942). 
Tal error, hoy en día, puede parecer trivial, pero en aquellos años se daba mucha importancia a la búsqueda de predecesores de los economistas que se estudiaban. La atribución a Jean Bodin de la primera formulación clara de la teoría cuantitativa del dinero era general. Sin embargo, el Comentario de Azpilcueta apareció doce años antes de la Réponse de Bodin. Además, el autor navarro desarrolla su primitiva teoría cuantitativa de una forma más completa que Bodin, empleándola como punto de partida para elaborar una teoría de paridad de poder adquisitivo del dinero en los cambios internacionales.

Este error de Ullastres, repetido por Carrera Pujal en su Historia de la economia española (aunque postulando la publicación de una edición anterior) ${ }^{6}$, fue corregido por José Larraz en su discurso de ingreso en la Academia de Ciencias Morales y Políticas en abril de $1943^{7}$. Larraz cita a Sayous, pero no a Ullastres. Insiste, como Sayous, en la importancia de Tomás de Mercado. También pasa a examinar alguno de los grandes tratados que Sayous no había estudiado, y se da cuenta de que la relación entre la masa monetaria, el nivel de precios y el cambio exterior había sido advertida mucho antes de que escribiera Mercado.

En un capítulo intitulado «El cuantitativismo monetario de Salamanca», Larraz traza una tradición de teoría monetaria que integra la serie: Vitoria, Soto, Azpilcueta, Mercado, Molina, Bañez, todos iusnaturalistas y moralistas españoles. Son ellos los maestros que Pereña iba a designar como los «artífices del pensamiento político español» y los fundadores de una escuela de teólogos y juristas. Mercado completó sus estudios en Salamanca e incorporó en su pensamiento económico las enseñanzas de Soto y Azpilcueta. La inclusión de Molina en la escuela me parece ahora más dudosa. Larraz refiere varias veces a los doctores en cuestión como la «escuela de Salamanca» y no creo que esta designación fuera injustificada.

Mi pequeño libro, The School of Salamanca, Readings in Spanish Monetary Theory, 1544-1605, se basa en los trabajos de Sayous, Ullastres, Carrera y Larraz. El tema me fue sugerido por el profesor Viñas Mey. El objeto del libro fue el de difundir entre los lectores de habla inglesa los resultados obtenidos en España ( $y$ en Francia por Sayous) y acaso de redondear un poco más el tema. La mitad del libro consiste en una serie de textos traducidos al inglés. En el estudio preliminar se considera el mercado monetario español en la segunda mitad del siglo xvi, los predecesores doctrinales de la escuela de Salamanca, los miembros de la escuela, y algunas de sus contribuciones a la teoría monetaria: es decir, sus doctrinas del origen y funciones del di-

- Carrera (1943), pp. 271.272.

${ }^{7}$ Larranz (1943). 
nero, su teoría del valor, y su teoría de los cambios. Se intenta esbozar la trayectoria de estas teorías en el pensamiento posterior, y se ofrece una breve bibliografía ${ }^{8}$.

En The School of Salamanca se explica que Vitoria y sus colaboradores fueron primariamente teólogos y juristas, pero que también emprendieron la difícil tarea de reconciliar la doctrina tomista con el nuevo orden económico:

«Aquí no nos ocuparemos de su enseñanza moral, ni siquiera de la totalidad de su teoría económica, sino sólo de una pequeña fracción de su labor, su análisis monetario» ${ }^{9}$.

El libro alcanzó su modesto objetivo. Produjo un cierto número de recensiones, tanto en España como en el extranjero, en su mayor parte benevolentes, y poco a poco la información presentada iba infiltrándose en el mundo de los historiadores y economistas extranjeros.

La publicación en 1954 de la Historia del Análisis Económico, de Schumpeter, estimuló el estudio de la doctrina escolástica en general y de la española en particular, puesto que el autor alude al «alto nivel del pensamiento económico español del siglo xvI» ${ }^{10}$, Schumpeter se basa mayormente en los trabajos del autor jesuita americano, Bernard Dempsey ${ }^{11}$. Profesa especial admiración por tres de los autores estudiados por Dempsey - Lessius, Lugo y Molina-, eligiendo a este último como su guía principal por el laberinto del pensamiento escolástico español. El único autor que Schumpeter conocía de primera mano fue Tomás de Mercado, y no podemos menos de sospechar que su lectura de Mercado había sido bastante rápida.

Cree Schumpeter que «algo justificado está hablar de una escuela de Salamanca de economistas», y concede que varios de sus miembros más destacados «happened to be Spanish», es decir, «resultaron ser españoles», pero afirma que su enseñanza no tenía nada de específicamente español. Es difícil aceptar esta opinión del maestro, por motivos ya mencionados en el texto de Sayous que acabo de leer.

Entre el gran número de autores, de diversas nacionalidades e ideologías, que han estudiado el pensamiento escolástico español, yo destacaría a Ray. mond de Roover, Wilhelm Weber, John Noonan, Pierre Vilar, Restituto Sierra Bravo, Barry Gordon, Francisco Gómez Camacho y Oreste Popescu (este último por su investigación del pensamiento escolástico hispano-americano).

${ }^{8}$ Grice-Hutchinson (1952), pp. 41.42 .

${ }^{9}$ Grice-Hutchinson (1952), pp. 41-42.

${ }^{10}$ Schumpeter (1954), p. 165.

"Depsey (1935) y (1943). 
De Vitoria y su escuela, más específicamente, se han ocupado el P. Demetrio Iparraguirre, cuyo estudio de la teoría del valor de Vitoria llenó una evidente laguna ${ }^{12}$, y el P. Gorosquieta Reyes, que ensanchó nuestros horizontes con su trabajo sobre el sistema de ideas tributarias de la escuela de Salamanca ${ }^{13}$. Todos ellos han hecho aportaciones importantes y han ayudado a formular más correctamente un concepto que, al parecer, sigue dando sus frutos.

Queda mucho terreno que explorar. De los 80 autores mencionados por Iparraguirre en 1954 como dignos de estudio it -la mayor parte de ellos pertenecientes a la tradición escolástica - sólo unos 15 han recibido alguna atención. Afortunadamente se está haciendo actualmente un gran esfuerzo para profundizar nuestros conocimientos tanto del pensamiento económico de la escolástica española en su totalidad como de la escuela de Salamanca que iba encajada en ella y que fue su núcleo más importante e influyente.

En conclusión, yo quisiera sugerir que se siga empleando el nombre de la "Escuela de Salamanca", consagrado ya por varias generaciones de historiadores, para referirse específicamente a Francisco de Vitoria, sus colegas, sus discípulos y sus principales continuadores, así en el campo económico como en el de las otras disciplinas a que dedicaron mayormente sus esfuerzos. Hay que tener en cuenta que a nosotros nos tocó estudiar su pensamiento económico y con este fin lo aislamos del resto de su enseñanza, pero en realidad va enlazado con ella y no sé si es muy razonable aceptar que un grupo de escritores puedan formar una escuela en un aspecto de su labor, pero no en otro. Es un problema complejo que no pretendo poder solucionar.

En cuanto a los demás doctores del siglo xVI, tendremos que contentarnos, por ahora, con el nombre genérico de la «escolástica española», o, como prefiere el profesor Popescu, la «escolástica hispana», sin olvidar la última novedad presentada por el erudito investigador argentino, "la escolástica indiana» ${ }^{15}$.

\footnotetext{
12 Iparraguirre (1957).

${ }^{13}$ Gorosquieta (1941).

14 Iparraguirre (1954).

is Popescu (1986).
} 


\section{BIBLIOGRAFIA}

Carrera Pujal, Jaime (1943): Historia de la Economía Española, Barcelona.

DEMPSEY, Bernard (1935): "The historical emergence of quantity theory», en Quaterly Journal of Economics, vol. 50, noviembre, pp. 174-184.

- (1943): Interest and Usury, with an introduction by Joseph Schumpeter, London.

ENDEMINN, Wilhelm (1874): Studien in der romaniscb-kanonistiscben Wirtschafts und Rechtslebre bis gegen Ende des 16 Jabrhunderts, Berlín.

Gorospuieta Reves, Javier (1941): El sistema de ideas tributarias en los teólogas y moralistas principales de la "Escuela de Salamanca" (siglos XVI y XVII), Madrid.

Grice-Hutchinson (1952): The School of Salamanca: Readings in Spanish Monetary Theory, Oxford.

Iparraguirre, Demetrio (1954): «Las fuentes del pensamiento económico en España, en los siglos xiu al xvı», en Estudios de Deusto, 2:" época, vol. II, núm. 3, enero-junio, pp. $79-113$.

- (1957): Francisco de Vitoria: una teoria social del valor económico, Bilbao.

Larraz, José (1943): La época del mercantilismo en Castilla, 1500-1700, Madrid.

Pereña Vicente, Luciano (1954): La Universidad de Salamanca, forja del pensamiento politico español en el siglo XVI, Salamanca.

Popescu, Oreste (1986): Estudios en la bistoria del pensamiento económico latinoamericano, Bogotá.

SAyous, André (1927): «Les changes de l'Espagne sur l'Amerique au xvrième siècle», en Revue d'Economie Politique.

- (1928): «Observations d'écrivains du xvrième siècle sur les changes», en Revue Economique Internationale, noviembre.

Schumpeter, J. (1954): History of Economic Analysis, Nucva York.

Ullastres Calvo, Alberto (1941-1942): "Martín de Azpilcueta y su comentario resolutorio de cambios», en Anales de Economia, octubre-diciembre y enero-marzo.

WEBER, Wilhelm (1959): Wirtschaftsetbik am Vorabend des Liberalismus, Münster. 